\title{
The 6E Approach to Person-centered Care
}

\author{
Sanjay Kalra ${ }^{1}$ and Ameya Joshi ${ }^{2}$ \\ 1. Department of Endocrinology, Bharti Hospital, Karnal, India; 2. Department of Endocrinology, Bhaktivedanta Hospital, Mumbai, India
}

DOl: https://doi.org/10.17925/USE.2019.15.2.72

$\mathrm{P}$ erson-centered care represents a process as well as a goal. Conceptualized as a philosophy of care, it is often difficult to integrate into practice. A lack of person-centered care may contribute to suboptimal outcomes in diabetes care. This editorial aims to improve the integration of person-centered care in diabetes practice by sharing and describing a simple approach to the process. It defines personcentered care as a framework with six components, alliteratively titled "the 6E list". This includes guidance for a physician to consider while providing diabetes care. The concepts are discussed in a hierarchal manner, facilitate understanding, and promote integration into daily practice.

\section{Keywords}

Person-centered care, communication, responsible person-centered care, diabetes

Disclosures: Sanjay Kalra and Ameya Josji have no conflicts of interest to declare in relation to this article.

Review Process: Double-blind peer review.

Compliance with Ethics: This article is an opinion piece and does not report on new clinical data, or any studies with human or animal subjects performed by any of the authors.

Authorship: The named authors meet the criteria of the International Committee of Medical Journal Editors for authorship for this manuscript, take responsibility for the integrity of the work as a whole and have given final approval for the version to be published.

Received: September 26, 2019

Accepted: October 26, 2019

Citation: US Endocrinology. 2019;15(2):72-3

Corresponding Author: Sanjay Kalra, Department of Endocrinology, Bharti Hospital, Kunjpura Road, Karnal, India 132001. E: brideknl@gmail.com

Support: No funding was received in the publication of this article.

\section{Person-centered care}

Person-centered care is a complex construct, with multiple facets to it. While the definition of personcentered care, or patient-centered care, is relatively straightforward, the practice of person-centered care is not easy. The Institute of Medicine defines person-centered care as "care that is respectful of and responsive to individual patient preferences, needs, and values" and that "ensures that patient values guide all clinical decisions". "This definition has been quoted by standard diabetes management guidelines as well. ${ }^{2}$ Person-centered care is a philosophy, a process, and a target. For a physician to practice person-centered care, she or he should be able to elicit patient preferences, needs and values, and be able to understand them and respect them. The physician should also be able to create a customized therapeutic plan, balancing biomedical needs with psychosocial reality. The complex, and often confusing, playing field of diabetes makes this difficult and challenging.

Various models have been proposed to simplify the process of person-centered care. The CARES acronym describes the attributes a of good diabetes care provider. ${ }^{3}$ The WATER approach describes the steps involved in motivational interviewing. ${ }^{4}$ The $10 \mathrm{R}$ list of responsible person-centered care explains the requirements of responsible interpretation and practice of person-centered care. ${ }^{5}$

\section{Ekman's model}

A recent model, developed by Ekman et al. ${ }^{6}$ focuses on the "person" rather than "patient" as a partner in health care. Ekman's model is based on three aspects of partnership: initiating, working, and safeguarding the partnership.

"Initiating the partnership" includes history taking and assessment of the person's needs, goals, and motivation. A detailed history and examination are required to plan an appropriate therapeutic approach. Apart from biomedical aspects, a personal and social history should also be taken. While this is being done, the need for and the rules of a stable, enduring partnership should be explored as well.

"Working the partnership" implies a focus on informed and shared decision making, congruent to the person's lifestyle, preferences, beliefs, values, and health issues. Information gleaned from clinical and laboratory assessment should be shared with the person to help her or him understand the limitations and benefits of various available treatment options.

"Safeguarding the partnership through documentation", the third aspect, highlights the need to document the individual's care preferences and decisions in records. This creates respect for the person's opinion, allows transparency, and facilitates continuity in care. Safeguarding of personcentered care is important for all stakeholders, including the person with diabetes, the healthcare provider, and the healthcare system. The person-centered care provider should ensure that individual choices and psychosocial peculiarities are recorded, the same way that individual medical notes are mentioned in records. 


\section{The 6E model}

In this editorial, we discuss the relevance of Ekman's model to diabetes care, and propose an expanded $6 \mathrm{E}$ model, based upon this. The $6 \mathrm{E}$ list is an alliterative and expanded version of Ekman's triptych, which includes and overlaps the concept shared in CARES and WATER.

Person-centered care requires a dialogue between person and provider. Ekman expands this dialogue to include not only real-time communication, but decision making and planning for the future as well. Realizing that one person with diabetes may meet multiple providers within the same health-care system, Ekman emphasizes the need for documentation. This is important, from a medicolegal perspective as well, to safeguard the healthcare provider in case of ambiguity

\section{Express willingness}

It must be noted that successful person-centered care depends upon the person's preference and willingness for the same. It is of utmost importance that behavior of the healthcare provider should convey willingness on his/ her part to take care of the patient's ailment. Actions, such as a warm greeting with a smile, polite dialogue showing respect for patient's views, and respectful conversation go a long way in portraying this willingness. There may be individuals who prefer to abdicate responsibility for self-care and decision-making to others. These "others" may be family members, friends, colleagues, or healthcare professionals. In such cases, the diabetes care provider should express willingness to initiate an equal partnership, while continuing with her or his professional responsibilities.?

\section{Establish a partnership}

Expression of willingness should sow seeds for durable partnership. Effective communication helps in establishing a strong partnership between person and provider. Durable partnerships are characterized by equipoise between both parties. Equipoise, in this context, implies balanced sharing of information and opinion, leading to optimal decision making. In a good number of cases, there is significant discordance between medical advice and its implementation by the patient. This can be bridged by joint decision making. ${ }^{8}$

\section{Empathize with all stakeholders}

Organizations such as American Diabetes Association, acknowledge that diabetes is commonly associated with distress. ${ }^{9}$ The astute diabetes care provider should be able to convey empathy to the person living with diabetes. An assurance that one understands the challenges and demands of living with diabetes is enough to encourage closer partnership in self-care. The same holds true when dealing with family members and close caregivers. ${ }^{9}$

\section{Explore partnerships}

This underlies the 360-degree care concept, where all potential partnerships for diabetes care should be explored. These include practitioners, paramedical personnel, patients, peers of the patient, and philanthropic organizations supporting diabetes care.10 Social groups, religious organizations, and online support groups may be unexpected sources of help.

\section{Expand horizons}

While working towards glucose control, one must endeavor to ensure that people living with diabetes are well informed and aware of their condition. Though it is difficult, one must aim to achieve true equipoise of information. ${ }^{8}$ This implies a (utopian) state where both patient and provider enjoy the same level of knowledge and information. This facilitates concordance in thought, in decision making, and action. To do so, one must continually strive to enhance one's own horizons, as well as the patient's. At times, differences in sociocultural backgrounds may lead to discordance or miscommunication. To bridge this gap, one must be open to receiving knowledge from all sources, whether conventional or otherwise. At the same time, the healthcare provider should not lose vision of their responsibility to provide evidence-based medicine.

Diabetes care is not limited to glycemic control; it includes holistic care of hypertension, dyslipidemia, and regular screening for complications. Hence, the diabetes practitioner should have adequate knowledge and skills in internal medicine.

\section{Express opinions in writing}

For continuity of care, and for medicolegal safety, one must express all opinions and preferences in writing. ${ }^{11}$ These should be part of medical records (preferably kept electronically or meticulously archived for a sufficiently long time-frame). This is especially true for incongruous decision making, such as non-initiation of insulin in situations which ideally demand so. Serial changes in health status of the patient if discussed with record can help patient take right decision.

\section{Summary}

Person-centered care is an important concept which is often difficult to incorporate into routine diabetes care. The 6E framework builds upon a pre-existing rubric, Ekman's model, to provide a pragmatic way of practicing person-centered care. The six steps of person-centered care are listed in an alliterative manner to help memorization and inclusion in daily practice. $\square$
1. Institute of Medicine (US) Committee on Quality of Health Care in America. Crossing the Quality Chasm: A New Health System for the 21st Century. Washington (DC): National Academies Press (US); 2001. Available at: www.ncbi.nlm.nih.gov/books/NBK222274/ (accessed November 1, 2019)
2. Inzucchi S, Bergenstal R, Buse J, et al. Management of hyperglycaemia in type 2 diabetes: a patient-centered approach. Position statement of the American Diabetes Association (ADA) and the European Association for the Study of Diabetes (EASD). Diabetologia. 2012;55:1577-96.
3. Kalra S, Kalra B. A good diabetes counselor 'Cares': soft skills in
diabetes counseling. Internet J Health. 2010;11:1-3.
Kalra S, Kalra B, Sharma A, Sirka M. Motivational interviewing: the water approach. Endocr J. 2010:57:S391.
5. Kalra S, Baruah MP, Unnikrishnan AG. Responsible patient-centered care. Indian J Endocrinol Metab. 2017;21:365-7.
6. Ekman I, Swedberg K, Taft C, et al. Person-centered care-ready for prime time. Eur J Cardiovasc Nurs. 2011;10:248-51.
7. Childress JF. The place of autonomy in bioethics. Hastings Cent Rep. 1990;20:12-7.
8. Tamhane S, Rodriguez-Gutierrez R, Hargraves I, Montori VM.

Shared decision-making in diabetes care. Curr Diab Rep. 2015;15:112.

9. Young-Hyman D, De Groot M, Hill-Briggs F, et al. Psychosocial care for people with diabetes: a position statement of the American Diabetes Association. Diabetes Care. 2016;39:2126-40.

10. Mayberry LS, Osborn CY. Family support, medication adherence and glycemic control among adults with type 2 diabetes. Diabetes Care. 2012;35:1239-45.

11. McCleery A, Devenny K, Ogilby C, et al. Using medicolegal data to support safe medical care: a contributing factor coding framework. J Healthc Risk Manag. 2019:38:11-8. 